very gallantly. Although it may be found that the book falls between three stools, this is really immaterial, for in his own mind the author has been able with tact and care to bridge this gap.

The book is divided quite simply into ætiology, early diagnosis, therapeutic technique and notes for the treatment of specific disorders; with a general section which includes prophylaxis of mental disorder and a section on war neurosis.

The book will have its greatest function in instructing those students and general practitioners who have an individual leaning towards psychiatry, psychotherapy, and particularly, perhaps, towards that branch which deals with border-line cases.

\section{WAR-TIME NURSE.}

Edited by J. M. Mackintosh, M.D. An Anthology of Ideas about the Care and Nursing of War Casualties. Oliver \& Boyd, Edinburgh. 1940. Price 5s.

The book is described on the title page as " An Anthology of Ideas about the Care and Nursing of War Casualties." The chapters are written by different authors, many of them very distinguished and specialists on their own subjects. It is a short work and written in a colloquial style; some chapters are superficial, and therefore not likely to be of much practical value except possibly to those who have had some war experience in the wards, and yet, by the nature of their voluntary effort, have been unable to ground themselves in professional fundamentals. On the other hand, some portions of the book are extremely well written and of value; special mention can be made of the section on the nursing of eye cases.

Some of the articles show a distinctly involved composition, and there are one or two glaring misprints. Yet these are minor blemishes in a book which is not meant to be a deep and thorough work for nurses, but is obviously intended as a mere preliminary survey in order to interest those who have volunteered their services in a time of stress. As such it is to be commended.

\section{LECTURES ON DISEASES OF CHILDREN.}

By Sir Robert Hutchison, Bart., M.D. P.R.C.P., and Alan MoncriefF, M.D., F.R.C.P.' Eighth Edition. Edward Arnold \& Co., London. 1940. Price 2ls.

This series of lectures has been so long before the medical profession, being first published in 1904, and it has passed through so many editions that a reviewer might be considered to have performed his duty by simply announcing that a new edition had appeared. This edition, however, differs from those which have preceded it in not being revised by the author himself but by a junior colleague, Dr. Moncrieff, who has undertaken the revision of the present edition, states in his preface that every part of the book has been revised and that the whole volume has been reset. It is apparent, therefore, that a reviewer is called upon to do more than merely wish the lecturers continued prosperity. To fall heir to the editorship of a popular book is always a heavy responsibility. More especially is this true when the subject-matter is the record of personal views and opinions as was the case with Sir Robert Hutchison's iectures on diseases of children. It was in virtue of this fact that they owed their value and their charm, for these lectures were eminently practical talks on some of the common problems in child life by one who was at the same time a master of clinical observation and the possessor of the unique gift of terse and picturesque language. As the lectures were delivered to students at the London Hospital their personal character and the frequent use of the first personal pronoun singular is not surprising. Naturally Dr. Moncrieff, not having had the privilege of delivering the lectures, adopts in his additions and corrections a more impersonal phraseology with the result that there is a want of continuity of style throughout the volume. When a book is revised one anticipates that the subject-matter will have been brought up to date and in line with current knowledge. It is therefore somewhat surprising to find so much stress laid on the use of mercury in the treatment of congenital syphilis, and such a statement as "I do not think you will often feel the need for neo-salvarsan in these young infants." Emphasis is laid on the difficulty of intravenous injections in the very young child because the veins are so small, although one of the illustrations (figure 19) of this particular lecture depicts the great enlargement of the veins of the scalp in congenital syphilis. Curiously, too, there is no mention of the arsenical preparation, spirocid, which is given per os and which has completely revolutionised within recent years the cure of congenital syphilis. It is also remarkable to find as the introductory sentence to the lectures on infant feeding, which in the preface are specifically stated to be completely new, " the subject of infant feeding has become unnecessarily complicated in recent years." Such a sentence might have had some justification when the lectures first appeared in 1904, but surely not at the present time. We would rather have thought that just the reverse was true. The old days of percentage feeding with complicated milk mixtures have gone, and to-day, when breast milk is not available, it is customary to employ undiluted cow's milk with or without the addition of lactic acid, and in amounts simply depending on the age of the child. Dr. Moncrieff's method is certainly not so simple, for he recommends dilution of the milk with water, and the addition of sugar and cream, and to be given in quantities depending on the weight as well as on the age of the child.

In a book which is ostensibly intended for the medical student ambiguity is a serious fault, and thus we should recommend that in any future edition it would be wise to revise certain statements, as, for example, the definition of nephrosis on p. 381 , that on p. 165 concerning the treatment of late or adolescent rickets (is there not confusion here between the disease itself and the deformities, resulting therefrom ?), that on p. 407 outlining the dietetic régime in cyclical vomiting (it is difficult to appreciate the rationale of the prohibition of chocolates and oranges in a disease in which glucose is considered so beneficial), and the remark on p. 390 that splenectomy is the best treatment for acholuric jaundice (we thought that this, indeed, was the only method of treatment). We are also of opinion that in any future edition the authors should take the opportunity of mentioning and emphasising in the lecture dealing with the clinical examination of sick children the necessity of a routine investigation of the urine. 